\title{
Student motivation to participate in asynchronous online discussions
}

\author{
Michelle L. Nelson, Kristy Oden, Laura L. Williams \\ Anderson College of Nursing and Health Professions, University of North Alabama, Florence, AL, United States
}

Received: February 28, 2019

DOI: $10.5430 /$ jnep.v9n9p6
Accepted: May 15, 2019

Online Published: May 31, 2019

URL: https://doi.org/10.5430/jnep.v9n9p6

\begin{abstract}
Participation in online learning environments, especially in asynchronous discussions, is a crucial component for student engagement in online learning. Learner motivation is associated with student success in the online learning environment. Intrinsic motivation, doing something because it is enjoyable or interesting, is associated with participation in discussion topic choices. External demands, both work and personal, can also affect a student's intrinsic motivation through altering their control. The purpose of this study was to examine the relationships between motivating factors and student participation in online asynchronous discussions. Post-licensure undergraduate (RN-BSN/RN-MSN) and graduate (MSN) students $(\mathrm{N}=350)$ were distributed an online anonymous survey consisting of ten questions. A response rate of $20 \%(\mathrm{~N}=69)$ was achieved, with $49 \%$ MSN (graduate) students $(\mathrm{n}=33)$ and 51\% RN-BSN/RN-MSN (undergraduate) students $(\mathrm{n}=36)$, participating in the survey. Seventy-nine percent of students were employed full-time. Graduate students $(65 \%)$ and undergraduate students (49\%) felt that their motivation to participate in discussions was related to their employment status. Seventy-nine percent of MSN students and $63 \%$ of undergraduate students reported that the current demands in their life affected their motivation to participate in online discussions. The majority of students felt that instructor participation in the discussion had no effect on their motivation to participate. When classified into undergraduate and graduate groups, graduate nursing students preferred a choice of discussion topics in which to participate $\left(\chi^{2}\right.$ $=10.851, p=.004)$. Providing students with discussion topic choices is associated with intrinsic motivation and increased online discussion participation.
\end{abstract}

Key Words: Choice, Motivation, Online discussions, Participation

\section{INTRODUCTION}

The shortage of registered nurses in the United States (US) continues to plague the healthcare system. This trend is expected to remain an issue for at least the next decade. ${ }^{[1]}$ In response to this shortage, the US has seen an increase in enrollment in entry-level baccalaureate nursing programs, as well as, registered nurse (RN) to Bachelor of Science in Nursing (BSN) (RN-BSN) programs, and master's and doctoral degree programs. ${ }^{[2]} \mathrm{A}$ growing number of these nursing degree programs are shifting to the online degree program format. Students are often drawn to online degree programs due to ease of accessibility and flexible scheduling. ${ }^{[3]}$ Flexible scheduling is essential for practicing RNs returning to school to pursue higher degrees, such as the RN-BSN degree and master's degree, due to work and family demands.

Online degree programs, while convenient, pose unique challenges for both students and faculty. According to data from the National Survey of Student Engagement (NSSE) 2013

\footnotetext{
*Correspondence: Michelle L. Nelson; Email: mlnelson1@una.edu; Address: Anderson College of Nursing and Health Professions, University of North Alabama, Florence, AL, United States.
} 
report, students enrolled in completely online programs were not as engaged in collaborative learning as those students who were in enrolled in traditional or blended degree programs. ${ }^{[4]}$ Students enrolled in fully online degree programs need to be organized, have effective time management skills, and be self-motivated. ${ }^{[3]}$ Faculty teaching in fully online programs must acknowledge the unique challenges related to student engagement and then cultivate an online learning environment that promotes meaningful dialogue with faculty and students.

Asynchronous discussion is a commonly used tool for engaging students in the online learning environment. ${ }^{[5]}$ Regarding asynchronous discussions, ${ }^{[6]}$ states that students' choice is a key element in the acquisition of knowledge through discussion. Chan et al. assert that students who are more motivated demonstrate more engagement in asynchronous discussions. ${ }^{[5]}$

There is robust literature on student motivation to participate in online discussions. ${ }^{[6-10]}$ However, few studies have examined online nursing students and asynchronous discussion participation. This study sought to examine the relationships between motivational factors and student participation in online asynchronous discussions.

\subsection{Literature review}

\subsubsection{Motivation}

Learner motivation is vital to the learners' success in an online learning environment and has reliably been linked to successful learning. ${ }^{[11,12]}$ Educator knowledge regarding students' motivation to participate in course activities is especially important, particularly in the online learning environment. ${ }^{[12]}$ Furthermore, educator knowledge regarding student motivation is key to the development of effective instructional experiences. $^{[13]}$

Motivation has historically been categorized as either intrinsic or extrinsic. Intrinsic motivation refers to doing something because it is of interest to the person or is rewarding to the person. ${ }^{[14]}$ Conversely, extrinsic motivation refers to a person doing something because of external rewards (e.g., grades, special privileges). ${ }^{[15,16]}$ Students who feel in control, or that they have a choice, tend to be intrinsically motivated. The level of intrinsic motivation is undermined when a student feels inhibited by external factors. ${ }^{[17,18]}$ Intrinsic motivation, in particular, has been found to be a critical component in student participation in asynchronous online discussions. ${ }^{[19]}$ However, the nursing student is often limited in participation by external motivational factors, such as work and family demands.

A literature search of nursing students' motivation resulted in Published by Sciedu Press a limited amount of research. The majority of the research involved motivation for choosing nursing as a career, ${ }^{[20-22]}$ traditional and nontraditional nursing student differences, ${ }^{[23,24]}$ and motivating factors for nurses related to continuing education. ${ }^{[25,26]}$ While the literature regarding motivation of nursing students to participate in online discussions is sparse, there is literature to support the general use of online discussions within the nursing student population. Hudson ${ }^{\text {[27] }}$ found that the incorporation of an online discussion board in a face-to-face nursing course improved overall student success in those students who participated fully. In addition, Campbell, Gibson, Hall, Richards, and Callery ${ }^{[28]}$ found that nursing students who participated in an online discussion were equally successful when compared to nursing students in a traditional face-to-face discussion. Additional research is needed to explore motivational factors in the online nursing student population and how they influence the achievement of academic outcomes.

\subsubsection{Choice}

The online learning environment has created the need to shift from the long established teacher-centered instruction approach to a learner-centered instruction approach. In a learner-centered instruction approach the educator is encouraged to support and assist learning as opposed to dictating what students should do. ${ }^{[29]}$ Learner-centered teaching "is achieved as the teacher assumes the role of facilitator and the students begin to direct their own learning through interaction, discussion, and collaboration with the teacher and classmates."[30]

One aspect to consider when adopting the learner-centered approach is allowing students the opportunity to choose the assignment in which they will participate. Cunnin, Macpherson, and Matteoni found that a student's willingness to participate in an online forum was directly linked to their ability to choose what discussion threads they write and read. ${ }^{[31]}$ Lin and Overbaugh also propose providing options for online discussions. ${ }^{[32]}$ Chan et al. found that students' decision to participate in an online discussion was positively impacted by their ability to choose from a variety of discussion topics. ${ }^{[5]}$ Furthermore, Chan et al. found that there was a positive correlation between discussion topic choice and student effort and performance. ${ }^{[5]}$ Brooks and Young assert that offering students choices in a classroom may enhance their feelings of self-determination and intrinsic motivation to participate in class activities. ${ }^{[33]}$ Permitting students to choose from a variety of discussion topics allows students the opportunity to discuss, research, and debate on a topic of genuine interest which in turn enhances the learning process. ${ }^{[5,34,35]}$ Additional research is needed to explore discussion topic choice in the nursing student population to determine how or if it 
impacts participation in online discussions.

\subsection{Purpose}

The purpose of this research was to examine the relationships between motivating factors and student participation in online asynchronous discussions.

\section{Methods}

\subsection{Sample}

Eligible participants in this study included all online nursing students enrolled in an online nursing course with required asynchronous discussions. Data collection occurred during fall 2017 and spring 2018 semester. A total of 191 graduate and 159 undergraduate students were invited to participate. An overall survey response rate of $20 \%$ was achieved $(\mathrm{N}=$ $69)$; the final sample consisted of 34 graduate and 35 undergraduate students. The response rate for graduate students was $18 \%$ and for undergraduate students $22 \%$. Table 1 lists sample characteristics.

Table 1. Sample characteristics

\begin{tabular}{lll}
\hline Demographic & Percentage & Total $(\boldsymbol{N})$ \\
\hline Gender & & \\
Female & $95.59 \%$ & 65 \\
Male & $4.41 \%$ & 3 \\
Race/Ethnicity & & \\
African American or Black & $13.24 \%$ & 9 \\
Caucasian or White & $83.82 \%$ & 57 \\
Hispanic or Latino & $1.47 \%$ & 1 \\
Native American or American Indian & $1.47 \%$ & 1 \\
Program Enrolled & & \\
RN-BSN & $30.43 \%$ & 21 \\
RN-MSN & $20.29 \%$ & 14 \\
MSN & $19.28 \%$ & 34 \\
English as First Language & & \\
$\quad$ Yes & $97.06 \%$ & 66 \\
No & $2.94 \%$ & 2 \\
Employment Status & & \\
Full-time & $79.71 \%$ & 55 \\
Part-time & $15.94 \%$ & 11 \\
Unemployed & $4.35 \%$ & 3 \\
\hline
\end{tabular}

\subsection{Design}

Quantitative, descriptive research was utilized to determine the relationships between motivating factors and student participation in asynchronous online discussions. Prior to conducting the research and after Institutional Review Board approval, researchers discussed the study with individual course leaders of courses that required asynchronous discussions. Once approval to assist in the research was obtained, course leaders were provided a standardized email to send out to all enrolled students in the courses that required asynchronous discussions (RN-BSN, RN-MSN, and MSN). The email initially explained the research study to the enrolled students and contained an electronic informed consent as well as a link to a confidential survey. If students agreed to participate, the survey provided consisted of 10 questions that could take up to five minutes to complete. An initial email was sent to students at or around mid-term of the semester followed by a reminder email approximately two (2) weeks later. The survey was closed at the end of the semester.

The 10-question survey included five (5) demographic questions, four (4) questions related to factors that affected motivation to participate in online discussions, and one (1) final question regarding discussion topic choice (assigned by instructor vs topics from which to choose from).

\section{Results}

The final sample consisted of 34 graduate and 35 undergraduate students $(\mathrm{N}=69)$. When comparing the groups regarding employment status the results were similar, with $79 \%$ of graduate students and $80 \%$ of undergraduate students employed full-time. Fewer undergraduate students (49\%) indicated that employment status affected their motivation to participate in online discussions when compared to their graduate counterparts (65\%). Similarly, sixty-three percent of undergraduate students reported that the current demands in their life affected their motivation to participate in online discussions, while $79 \%$ of graduate students reported the same. When asked what affected their motivation to participate in online discussions the most, the results were similar with $38 \%$ of undergraduate and $32 \%$ of graduate students indicating that the preference of discussion topic affected their motivation, $53 \%$ of undergraduate students and $62 \%$ of graduate students stated that other life demands affected their motivation, and $9 \%$ of undergraduate students and $6 \%$ of graduate students indicated that nothing affected their motivation to participate in online discussions. Interestingly, a higher percentage of graduate - students $(88 \%)$ indicated they preferred a number of discussion topics to choose from when compared to their undergraduate counterparts $(60 \%)$. Regarding the same question (discussion topic preference), no graduate students indicated they wanted discussion topics assigned by the instructor while $29 \%$ of undergraduate students indicated they preferred a topic to be assigned. Finally, students were asked if instructor participation affected their motivation to participate in an online discussion. The results were similar, with $65 \%$ of undergraduate students, and $71 \%$ of graduate students reporting that instructor participation did not affect their motivation to participate. Table 2 lists results of motivation questions. 
Table 2. Results of motivation questions

\begin{tabular}{|c|c|c|}
\hline Question & Undergraduate $(n=35)$ & Graduate $(n=34)$ \\
\hline My employment status affects my motivation & True 17 (49\%) & True 22 (65\%) \\
\hline to participate in online discussions. & False $18(51 \%)$ & False 12 (35\%) \\
\hline $\begin{array}{l}\text { The current demands in my personal life affect } \\
\text { my motivation to participate in online } \\
\text { discussions. }\end{array}$ & $\begin{array}{l}\text { True } 22(63 \%) \\
\text { False } 13(37 \%)\end{array}$ & $\begin{array}{l}\text { True } 27(79 \%) \\
\text { False } 7 \text { (21\%) }\end{array}$ \\
\hline $\begin{array}{l}\text { My motivation to participate in an online } \\
\text { discussion is most affected by: }\end{array}$ & $\begin{array}{l}\text { Preference of topic } 13(38 \%) \\
\text { Life demands } 18(53 \%) \\
\text { Nothing } 3(9 \%)\end{array}$ & $\begin{array}{l}\text { Preference of topic } 11(32 \%) \\
\text { Life demands } 21(62 \%) \\
\text { Nothing } 1(6 \%)\end{array}$ \\
\hline Please specify your discussion preference: & $\begin{array}{l}\text { Discussion topic assigned by instructor } \\
10(29 \%) \\
\text { Number of discussion topics from which } \\
\text { to choose } 21(60 \%) \\
\text { No preference } 4(11 \%)\end{array}$ & $\begin{array}{l}\text { Discussion topic assigned by instructor } \\
0(0 \%) \\
\text { Number of discussion topics from } \\
\text { which to choose } 30(88 \%) \\
\text { No preference } 4(12 \%)\end{array}$ \\
\hline $\begin{array}{l}\text { I am more motivated to participate in a } \\
\text { discussion when my instructor participates. }\end{array}$ & $\begin{array}{l}\text { Yes } 12(35 \%) \\
\text { No } 22(65 \%)\end{array}$ & $\begin{array}{l}\text { Yes } 10(29 \%) \\
\text { No } 24(71 \%)\end{array}$ \\
\hline
\end{tabular}

Pearson chi-square was conducted to determine if relationships existed between undergraduate and graduate students regarding motivation to participate in online asynchronous discussions. Graduate students preferred to choose their own topic $\left(\chi^{2}=10.839, p=.001\right)$ significantly more than under- graduate students. There were no differences in undergraduate and graduate students regarding other motivating factors such as employment status, personal demands, or instructor participation. Table 3 reports results for each relationship.

Table 3. Undergraduate and graduate student participation in online asynchronous discussions

\begin{tabular}{lcc}
\hline Question & $\chi^{2}$ & $\boldsymbol{p}$ \\
\hline My employment status affects my motivation to participate in online discussions. & .833 & .361 \\
The current demands in my personal life affect my motivation to participate in online discussions. & 2.541 & .111 \\
My motivation to participate in an online discussion is most affected by: preference; life demands; nothing & .633 & .729 \\
Please specify your discussion preference. (assigned by instructor; prefer topics to choose from) & 10.839 .001 \\
I am more motivated to participate in a discussion when my instructor participates. & .01 & .920 \\
\hline
\end{tabular}

\section{Discussion}

Graduate students prefer choice significantly more than undergraduate students. Graduate student work is associated with a higher level of scholarship and synthesis of learning; thus the graduate student may regard choice of discussion topics as a higher level of independent learning. This finding is consistent with previous studies. ${ }^{[5,34,35]}$ There were no significant differences between graduate and undergraduate students regarding the impact in which employment status or family demands affects discussion participation. However, almost half of undergraduate (49\%) and two-thirds of graduate $(65 \%)$ students reported that employment status affected their participation in discussions. Furthermore, $63 \%$ of undergraduate and $79 \%$ of graduate students reported that family demands affected their participation in online discussions. So although there was not a statistical difference, employment and family demands seriously impact student

Published by Sciedu Press motivation to participate in online discussions.

\section{Limitations}

The limitations to this study must be recognized. First, the sample size was small $(\mathrm{N}=69)$, although the number of undergraduate and graduate students was almost equal. The sample was mostly female $(n=65)$, white $(n=57)$, and employed full time $(n=55)$, so generalizability to the online student's discussion preferences is limited. It is likely that the majority of this sample represents the Southeastern states, and would not be generalizable to online students from different areas of the US. The response rate (20\%) is acceptable for a convenience sample, yet still a small response rate. Finally, the data collection occurred over two semesters; it is possible that results would have been more generalizable if data were collected for a longer period of time. 


\section{Conclusion}

Online undergraduate (RN-BSN; RN-MSN) and graduate nursing degrees are increasingly popular due to the flexibility of the online schedule and the desire of the student to further their nursing career. The same intrinsic and extrinsic motivational factors that convince the student to further his/her nursing education should be considered when developing learning opportunities in the online nursing curriculum. Consequently, those same motivating factors (work and family demands) may be barriers to student participation. The large numbers of online nursing students places serious demands on the limited nursing faculty throughout the country. Faculty should work smarter and not harder to produce constructive online learning opportunities for students. Asynchronous discussions should involve student choice of discussion topics, thus supporting student-driven learning, student engagement in the online learning environment, and a richer, deeper discussion of the course concepts. Further research should include more investigation into online student's motivation with larger sample sizes representing the US in multiple undergraduate (RN-BSN; RN-MSN) and graduate online programs.

\section{CONFLicts OF InTERest Disclosure}

The authors declare that there is no conflict of interest.

\section{REFERENCES}

[1] American Association of Colleges of Nursing. Fact sheet: Nursing shortage. 2017. Available from: http: //www . aacnnursing.org/Portals/42/News/Factshee ts/Nursing-Shortage-Factsheet-2017.pdf

[2] American Association of Colleges of Nursing. AACN finds slow enrollment growth at schools of nursing. 2014. Available from: https://www . aacnnursing.org/News-Information/P ressReleases/View/ArticleId/21683/slow-enrollment

[3] Hampton D, Pearce PF. Student engagement in online nursing courses. Nurse Educator. 2016; 41(6): 294-298. PMid:27175833 https://doi.org/10.1097/NNE.0000000000000275

[4] National Survey of Student Engagement. A Fresh Look at Student Engagement: Annual Results 2013. Bloomington, IN: Indiana University Center for Postsecondary Research.

[5] Chan K, Lai S, Leung H, et al. Engagement in online asynchronous discussions: Roles of students' interests and preferences. Available from Idrus RM, Zainuddin N. Proceedings of the 11th International Conference on e-Learning, Kuala Lumpur, Malaysia. Kidmore End, UK: Academic Conferences and Publishing International Limited. 2016 June; 32-26.

[6] Rovai AP, Bamum KT. On-line course effectiveness: An analysis of student interactions and perceptions of learning. International Journal of ELearning \& Distance Education. 2007; 18(1): 57-73.

[7] Capsi A, Blau I. Social presence in online discussion groups: Testing three conceptions and their relations to perceived learning. Social Psychology of Education. 2008; 11(3): 323-346. https: //doi.org/10.1007/s11218-008-9054-2

[8] Gao F, Putnam RT. Using research on learning from text for inform online discussion. Journal of Educational Computing Research. 2009; 41(1): 1-37. https://doi.org/10.2190/EC.41.1.a

[9] Kim HK, Bateman B. Student participation patterns in online discussion: Incorporating constructivist discussion into online courses International Journal on E-Learning. 2010; 9: 79-98.

[10] Xie. What do the numbers say? The influence of motivation and peer feedback on students' behaviour in online discussions. British Journal of Educational Technology. 2013; 44: 288-301. https: //doi.org/10.1111/j.1467-8535.2012.01291.x

[11] Bonk CJ, Khoo E. Adding some tech-variety. 2014. Available from http://tec-variety.com/TEC-Variety_eBook_5-4.pdf
[12] Clayton K, Blumberg F, Auld DP. The relationship between motivation learning strategies and choice of environment whether traditional or including an online component. British Journal of Educational Technology. 2010; 41(3): 349-364. https://doi.org/10.1111/ j.1467-8535.2009.00993.x

[13] Tallent-Runnels MK, Thomas JA, Lan WY, et al. Teaching courses online: A review of the research. Review of Educational Research. 2006; 76(1): 93-135. https://doi.org/10.3102/0034654307 6001093

[14] Lin CH, Zhang Y, Zheng B. The roles of learning strategies and motivation in online language learning: A structural equation modeling analysis. Computers \& Education. 2017;113: 75-85. https : //doi.org/10.1016/j.compedu . 2017.05.014

[15] Ryan RM, Deci EL. Intrinsic and extrinsic motivations: Classic definitions and new directions. Contemporary Educational Psychology. 2000a; 25(1): 54-67. PMid:10620381 https ://doi .org/10.100 6/ceps.1999. 1020

[16] Sun JC-Y, Hsieh P-H. Application of a gamified interactive response system to enhance the intrinsic and extrinsic motivation, student engagement, and attention of English learners. Educational Technology \& Society. 2018; 21(3): 104-116.

[17] Lee J, Martin L. Investigating students' perceptions of motivating factors of online class discussions. International Review of Research in Open and Distributed Learning. 2017; 18(5): 148-172. https://doi.org/10.19173/irrodl.v18i5.2883

[18] Mandigo JL, Holt NL. Putting theory into practice: How cognitive evaluation theory can help us motivate children in physical activity environments. Journal of Physical Education, Recreation \& Dance. 1990; 71(1): 44-49. https ://doi .org/10.1080/07303084. 200 0.10605984

[19] Hall MT, Marshall JE. Intrinsic and Extrinsic Motivation within the Context of Modern Education. In E. Railean, G. Walker, A. Elçi, L. Jackson (Eds.), Handbook of Research on Applied Learning Theory and Design in Modern Education. Hershey, PA: IGI Global. 2016; 292-308. https://doi .org/10.4018/978-1-4666-9634-1

[20] McLaughlin K. Changing motivation. Nursing Standard. 2010; 24(51): 61. https://doi.org/10.7748/ns.24.51.61.s52

[21] Newton JM, Kelly CM, Kremser AK, et al. The motivations to nurse: An exploration of factors amongst undergraduate students, registered nurses, and nurse managers. Journal of Nursing Management. 2009; 17(3): 392-400. https://doi.org/10.1111/j.1365-2834.20 $08.00945 \cdot \mathrm{x}$ 
[22] Raines DA. What attracts second degree students to a career in nursing? Online Journal of Issues in Nursing. 2011; 16(1): 8.

[23] Mullen PA. Use of self-regulating learning strategies by students in second and third semesters of an accelerated second-degree baccalaureate nursing program. Journal of Nursing Education. 2007; 46(9): 406-412. https://doi.org/10.2320/materia.46.406

[24] Ofori R, Charlton JP. A path model of factors influencing the academic performance of nursing students. Journal of Advanced Nursing. 2002; 38(5): 507-515. PMid:12028284 https://doi.org/10.1 $046 / j .1365-2648.2002 .02212 \cdot x$

[25] Altman TK. Registered nurses returning to school for a bachelors degree in nursing: Issues emerging from a meta-analysis of the research. Contemporary Nurse. 2011; 39(2): 256-272. https: //doi.org/10.5172/conu.2011.39.2.256

[26] Mackereth P. An investigation of the developmental influences on nurses' motivation for their continuing education. Journal of Advanced Nursing. 1989; 14(9): 776-787. https://doi.org/10.1 111/j.1365-2648.1989.tb01642.x

[27] Hudson, KA. Teaching nursing concepts through an online discussion board. The Journal of Nursing Education. 2014; 53(9): 531-536. PMid:25138567 https : //doi.org/10.3928/01484834-20140 820-01

[28] Campbell M, Gibson W, Hall A, et al. Online vs. face to face discussion in a web-based research methods course for postgraduate nursing students: A quasi-experimental study. Science Direct. 2006; 45(2008): 750-759. PMid:17306272 https://doi.org/10.101 $6 / j$. ijnurstu.2006.12.011
[29] Hanewicz C, Platt A, Arendt A. Creating a learner-centered teaching environment using student choice assignments. Distance Education 2017; 38(3): 273-287. https://doi.org/10.1080/01587919.2 017.1369349

[30] Manning VC. Learner-centered teaching. Radiologic Science \& Education. 2017; 22(2): 23-31.

[31] Cunnin B, Macpherson A, Matteoni JA. Bump up the energy: Engaging students in online forums. Collected Essays on Learning and Teaching. 2011; 4: 38-45. https://doi.org/10.22329/cel t.v4i0.3271

[32] Lin S, Overbaugh RC. The effect of student choice of online discussion format on tiered achievement and student satisfaction. Journal of Research on technology in Education. 2007; 39(4): 399-415. https://doi.org/10.1080/15391523.2007.10782489

[33] Brooks CF, Young SL. Are choice-making opportunities needed in the classroom? Using self-determination theory to consider student motivation and learner empowerment. International Journal of Teaching and Learning in Higher Education. 2011; 23(1): 48-59.

[34] Al-Huneidi A, Schreurs J. Constructivism based blended learning in higher education. In Lytras M, Ruan D, Tennyson R, Ordonez De Pablos P, Garcia Penalvo F, Rusu L. (eds). Information Systems, E-Learning, and Knowledge Management Research. Springer Berlin Heidelberg; 2013. https : //doi .org/10.1007/978-3-642-358 79-1_74

[35] Fosnot CT, Perry, RS. Constructivism: A psychological theory of learning. In Fosnot, C.T., \& Perry, R.S., (Eds.). Constructivism: Theory, perspectives, and practice. 2nd ed. New York: Teachers College Press; 2005. 